\title{
Level of Psychological Burnout of a Sample of Secondary Phase Teachers in Ma'an Governorate and Its Relationship with Some Other Variables
}

\author{
Omar Alkhateeb $^{1}$, Osama M. Kraishan ${ }^{1} \&$ Raid Omar Salah ${ }^{1}$ \\ ${ }^{1}$ Faculty of Educational Sciences, AL-Hussain Bin Talal University, Jordan \\ Correspondence: Osama M. Kraishan, Faculty of Educational Sciences, AL-Hussain Bin Talal University, Jordan. \\ E-mail: okraishan@yahoo.com
}

Received: January 29, 2015

Accepted: February 28, 2015 Online Published: May 27, 2015

doi:10.5539/ies.v8n6p56

\author{
URL: http://dx.doi.org/10.5539/ies.v8n6p56
}

\begin{abstract}
This study aimed at identifying the level of psychological burnout of a random sample of secondary phase teacher in Ma'an Governorate and its relationship with some other variables. The study sample consisted of 80 male and female Islamic education teachers in the schools of Ma'an Governorate in the southern part of Jordan. To this end, the researchers used Maslach's scale for identifying the psychological burnout of teachers. Findings show that Islamic education teachers suffer a mid-level of psychological burnout and lack of achievements. In addition to the mid-level of general psychological burnout, findings also show that teachers suffer from a low-level dullness.
\end{abstract}

Keyword: psychological burnout, Islamic education, Maslach's scale

\section{Introduction}

Educational matters and their problems gain a great sense of concern on national, Regional, or global levels. A large number of international organizations, such as UNESCO, ILSCO, and governmental institution along with private associations exert massive efforts to develop education and solve the related problems which impede the educational process.

Nowadays, education is considered one of the most important issues on the global level, as it is not taken as a job, nor is it a work that requires a set of information. Instead, education is considered a profession like medicine and engineering, among others (Badawi, 2006; Jaroudi, 2008). Education, from other perspectives, entails many risks due to the changing societal outlook at the educational system, including the change in students' conducts along with the altered perspective toward education and teaching because of the quick technological development all over the world (Schulz, 2007; Aljaberi, 2000). Education has now been depending on knowledge and the economics of knowledge. Pertaining to the objectives of these knowledge-based economics, the challenge of educational reformation is not only related to enlarging the body of knowledge or academic attainment based on examinations, but it also seeks to alter the teaching-learning process and training to align with the aims of knowledge-based economics (Hargreaves \& Shaw, 2001). These aims require a great deal of interest in the criteria of teachers which clarifies performance requirements, which include: "knowledge, skills needed for the teachers, responsibility, Accountability for those who work in schools" (The High House of Education, Qatar, 2008; Makarakis, 2005; Badawi, 2006).

Teaching requires the availability of specific personal traits along with the professional efficiencies and characteristics of the teacher in order to maintain success in his career. Such characteristics include: "composure, justice, sense of humor, patience, flexibility, collaboration, warm-heartedness, consideration of students' feelings, provocation of students thoughts, and interaction with students, according to their capabilities and measures" (Nasser, 2000). Today, the educational process witnesses negative practices from some teachers which reflect their obstinacy and their unusual nature. The reasons behind those practices can be summarized as follows: personal problems, psychological burnout, and frustration because of the belief that others hate them especially at their work (Kloke \& Smith, 2005). Another reason for that is that teachers shoulder hectic duties which make a harsh experience for them which results in both internal and external pressure (Schonfeld, 2001).

The internal and external pressures, which the teacher undergoes, can result in psychological and physical 
exhaustion that would make the teacher careless of his students. They also result in lack of motivation for the teacher, routine kind of work, and resistance of change which victimizes the teacher in a Psychological Burnout, which is firstly used by the American psychotherapist, Herbert Freudenberger, in 1974. Psychological burnout basically means the feeling of exhaustion, indulgence, and overburdening (Albatal, 2000).

Both Maslach and Jackson define psychological burnout as a feeling for the individual of emotional exhaustion, Depersonalization, Low Personal Accomplishment, which aligns with Maslach and Leiter definition (Bilge, 2006) which refers to the change of individuals conducts, attitudes, physical status toward work, resulting in emotion and low personal accomplishment.

Furthermore, psychological burnout is defined as a state of agitation, tension, and professional dissatisfaction, which befalls workers at the social level and in the educational-teaching behavior, resulted from the psychological pressures out of burdens of duty. As a result of that, the workers powers and efforts are depleted which, consequently, causes a low-quality and unacceptable performance (Alhayek, 2000; Noushad, 2008).

The factors of the Psychological burnout might include professional pressures that the teacher can neither handle nor face. Some of these factors are: long span work hours, consecutive classes without break, inability to shoulder the assigned duties, teaching overload, multiple tasks to confront the upcoming troubles, personal traits of the teacher (Maher, 1983). Finally, weak bodily and psychological health plays a significant role in the Psychological burnout of the teacher (Gugliemi \& Tatrow, 1988).

From a behaviorist perspective, psychological burnout is an internal status that afflicts the individual, such as anxiety and anger due to environmental reasons (Rashdan, 1995). The following figure shows Schwab sample of Psychological burnout for Teachers (Dardeer, 2007).

Table 1. Sources of psychological burnout

\begin{tabular}{ll}
\hline Profession-Based Factors & Personality-Based Factors \\
\hline Irrelevance in decision making & Profession Expectations \\
Lack of Social support & Years of experience \\
Ambiguity of role & Type and age \\
Conflict of role & Educational status \\
Accompanied Behaviors & Aspects of Psychological Burnout \\
Fatigue with the least of effort & Emotional exhaustion \\
Increasing the average of absence & Depersonalization \\
Quitting the job & Low personal accomplishment \\
\hline
\end{tabular}

According to Maslach's definition of Psychological Burnout, it passes through three stages, which are looked at as integrated chain (Kharabsheh \& Ahmad, 2005).

First: Emotional Exhaustion Stage

This exists due to work pressure deterioration of intrapersonal relationships which subsequently makes the enthusiastic and idealistic teacher willing to quit his job as a natural reaction to the above capacity work. Emotional Exhaustion is a stage of pressure whose primary cause is the unbalance between work requirements and the abilities needed for work accomplishment.

Second: Depersonalization Stage

In this stage, the emotionally exhausted and the nervously tired teacher attempts at facing the psychological pressure caused by work by acting passively toward others. In Maslach's terms, Depersonalization means that teachers possess passive attitude toward students, their guardians, and his colleagues where they create barriers between them and others, causing the gap to increase. This stage is a result of the former one, as it is an emotional reaction to the unbalance in which the teacher feels anxious and tired because of the pressure work requirements engender.

Third: Low Personal Accomplishment Stage

The teacher becomes dissatisfied with his professional performance and accomplishment. In few years, this 
teacher comes to the conclusion that he has not been to the dreamt of expectations and his idealistic values. Therefore, in this stage the teacher undergoes a group of changes in his attitudes and behaviors, as he deals with others mechanically and gets busy off them to fulfill his own desires which result in low duty commitment. Yet, if a teacher suffers from psychological or professional pressure at work does not necessarily mean that that teacher has Psychological Burnout, as he is not able to cope with these kinds of pressure or the upcoming problems (Nushad, 2008).

Psychological burnout might cause a variety of negative effects upon the teacher. In terms of work, the real effect of Psychological burnout lies in his lack of creativity, inability to diagnose problems and find solutions, occupational dissatisfaction, feeling incompetent, and lack of commitment to attend which make discourage him of teaching (Tina, 2008).

From a bodily perspective, Psychological burnout increases feeling of sickness, stress, high blood pressure, backache, headache, nausea, sleep disorder, recurrent flue, and viral arthritis. Psychologically speaking, Psychological burnout leads low self-esteem, feeling miserable, low self-confidence, loss of memory, feeling sad and disable, depression, frustration, irritability, anger, loss of sense of humor, and carelessness of personal priorities (Schonfield, 2001). In addition, it increases the degree of fatigue, exhaustion, sleep problems, emaciation, frustration, passivity toward students and their guardians, and pessimism (Bakker, Schanfeli, Sixma, Bosveld, \& Van, 2000).

Sociologically speaking, Psychological burnout results in deterioration of his social relationships with colleagues and students, as he remains in solitude which affects his familial relationship (Alfrehat \& Rabadi, 2010; Cano-Garcia et al., 2005). Moreover, Psychological burnout can affect teachers regardless to their academic majors, whether theirs are theoretical as Arabic Language or Islamic Studies, or applied materials such as Science or Mathematics.

As for teacher of Islamic Education, working in this filed might cause frustration for teachers in education because of many factors, such as weaknesses of students, lack of concentration in classroom, lack of clear objectives that align with reality, insufficiency of Islamic Education classes, weakness of the teacher and the sole dependency on the teacher. Also, some religious concepts are troublesome to learn which makes teachers frustrated. To clarify, the Islamic creed is basically related to studying metaphysical notions as (Heaven, Hell, jinn, and the straightway). These notions are extremely abstract which have to be taught in early stages by proper means to make them understandable for students. Yet, teachers must deviate from picturesque representations of those concepts and provide related examples instead. Therefore, teachers find it difficult to deliver such concepts to the students in elementary stages which might discourage teachers.

Accordingly, educators have recently called for reformation and improvement of education along with developing both related financial and human capabilities (NCHR, 2006). Thus, this study aims at unveiling the degree of Psychological burnout of Islamic Education teachers in Ma'an, south of Jordan.

\subsection{Problem and Significance of the Study}

The problem of study can be specified by posing the following question:

What is the degree of psychological burnout for Islamic Education in MOE schools in Ma'an. This question is subdivided into:

1) What is the degree of psychological burnout for teachers of Islamic Education in Ma'an pertaining Maslach's standard for psychological burnout with its three dimensions: (Emotional Exhaustion, Depersonalization, and Low Personal Accomplishment)

2) Are there any statistical implications of difference, in $(a=0.05)$ in the level of psychological burnout for teachers, that echoes in the academic level and years of experience.

\subsection{Significance of the Study}

Revealing the reasons of psychological burnout for teachers of Islamic Education, which can help in better planning to improve the status of teachers, develop the environment of work, and lessen the factors that cause pressure upon teachers.

\subsection{Action Terminology}

Psychological Burnout: is what happens to teachers including fatigue, emotional, mental, and bodily exhaustion, burden of overload, depersonalization, passive attitude toward students and society, and low personal accomplishment. It can be manifested by the frequency of the psychological status of the teacher based on the standard of psychological burnout with its subsidiary dimensions, classified into three levels: Emotional 
Exhaustion, Depersonalization, and Low Personal Accomplishment.

Islamic Education Teachers are teachers who teach Islamic Education in Ma'an schools in the south of Jordan in the scholastic year 2013/2014 for secondary stage.

\subsection{Constraints of the Study}

Generalization of results is determined by the following constraints:

1) The study is based on using an Arabic translation of Jackson's and Maslach's standard of psychological burnout with its three dimensions. Accordingly, the results of this study are determined by the psychomotor traits that are available about the Arabic version of the standard.

2) Generalization of the results of this study is specified by the traits of sample study and by their honesty while answering the sections of the standard.

\subsection{Previous Studies}

Researchers have conducted many previous studies pertaining to psychological burnout of teachers in different majors. Previous studies have proven useful to the analysis of the current study and to compare that with the results accomplished by the researchers. Thus, the studies are arranged by date.

Tawalbeh (1999) has carried out a study regarding teachers psychological burnout in schools in Irbid, Mafraq, Ajlun, and Jerash. Maslach standard has been applied to a sample of one hundred male and female teachers. The results have shown that Computer teachers are highly suffering from psychological burnout. Yet, there was not any difference that bears a statistical significance such as factors related to gender, type of assignment, number of classes, or the number of schools that teachers teaches in.

The study of Zghoul, Khresha, and Khaldi (2003) aimed at measure the degree of psychological burnout of teachers and its relationship with their comprehension of the leading pattern of ALkarak male and female headmasters. Maslach's standard has been applied to a sample of (305) male and female teachers. The results has shown a high sense of psychological burnout for male and female teachers, related to the emotional exhaustion, and to a lesser extent related to depersonalization and low personal accomplishment. Statistical differences have been found pertaining to the degree of the psychological burnout such as gender; the degree of psychological burnout for male teachers is higher than that of female teachers.

Mustafa's (2004) study aimed at recognizing the degree of emotional exhaustion of secondary male and female teachers in Alkhartoum, in the light of some professionals and demographic variables, as the number of the sample was 108 male and female teachers. The study has revealed the presence of the psychological burnout on both simple and mediate levels. Lack of distinctive features of the emotional exhaustion is due to the nature of the teacher, the nature of the material. In addition, there are some distinctive features that are related to the marital status of the teacher; yet, age and years of experience are excluded.

Patrick, Man, and Raymond (2005) conducted a research about the impact of some demographic characteristics upon the psychological burnout for secondary school teachers in Hong Kong. As Maslach standard applied, the results have shown that by comparing the level of psychological burnout for teachers in North America with that of Hong Kong teachers, they are on the same level regarding the emotional exhaustion and low personal accomplishment. Yet, pertaining to depersonalization, Hong Kong teachers were less than North America teachers; also, unqualified teachers are more exposed to psychological burnout.

Ahmad and Alkhrabsheh's (2005) study focused on figuring out the level of psychological burnout for the teachers of students with learning disabilities, in Jordan. The study unveiled the degree of the psychological burnout for teachers of students with learning disabilities, which is moderate on both emotional exhaustion and depersonalization; while the degree was high on low personal accomplishment stage. The level of psychological burnout for experienced teachers is less that the inexperienced teachers. All in all, the study has shown that low personal accomplishment is more apparent in female teachers than male ones.

Welko and Elvira (2008) conducted a study to measure the percentage of psychological burnout for both teachers and principals and its relationship with the accomplishment in work. Maslach standard was applied to a sample of 215 teachers and 514 principals. The results have shown a relationship between accomplishment in work and the psychological burnout, as low accomplishment is a crucial factor of the rise of psychological burnout level.

The study of Saeed and Qaryouti (2010) aimed at revealing the levels of psychological burnout for a sample of 200 male and female teachers of students with learning disabilities in Oman. The study showed that the level of psychological burnout for female teachers is low, and levels of psychological burnout vary depending on specialization and degree; while the levels have not changed depending on marital status for the teacher. Also, 
the degree of psychological burnout is directly proportional with the economic status of the students.

The purpose of Alfrehat and Rabadi's (2010) study is to uncover the levels of the psychological burnout for kindergarten female teachers in Ajlun and the impact of the type of kindergarten, whether it is governmental or private, the salary, years of experience, degree, and number of students in class upon teachers. The community of the study included all kindergarten teachers both private and governmental, 120 female teachers. Maslach's standard was used as a tool of this study. The results of the study showed that kindergarten teachers in Ajlun suffer from a high sense of psychological burnout, as the results did not show any distinctive features with statistical importance related to type of kindergarten, years of experience, degree, or number of students in class while the study showed that differences appear depending on the salary teachers whose income is less that 100 JD.

Risheh (2010) conducted a study whose purpose is to reveal the levels of psychological burnout and the satisfaction of living scale for female teachers of students with learning disabilities and their relationship with factors such as experience, gender, and type of disability of 120 male and female teachers sample in Asyout, Egypt. Thus, the results showed that those teachers suffer from psychological burnout in a moderate level, as they do not have a sense of satisfaction of the living scale. Also, there is not any variation of the degree of the psychological burnout regarding experience; rather, it changes as gender and type of disability vary.

According to the study of Alshuyoukh (2011), it was directed toward uncovering the degree of psychological burnout for secondary schools for females in Alqatif and its relationship with the attitude toward the profession of teaching. The sample of the study consisted of 100 female teachers' random sample. In order to implement the objective of the study, the researcher chose two standards: Gildred's standard for psychological burnout and teacher's attitudes standard. The results have unveiled a high degree of psychological burnout for secondary teachers who work in Alqatif schools. In addition, they indicated that those teachers possess a negative attitude. Thus, to figure out the relationship between the psychological burnout and the attitude toward teaching, Person correlation factor was applied between the degrees of research sample, as teachers answered that standard. The correlation factor indicated that there is a good correlational relation ranking 0.78 between the degree of psychological burnout and the attitude toward teaching. This relation showed that if the degree of psychological burnout increased, the value of positive attitude decreased, and the negative attitude increased toward teaching.

Alsalkhi's (2013) study aimed at recognizing the degree of psychological burnout for Islamic education teachers in private schools in Amman taking into consideration the factors of gender, degree, years of experience, monthly income, age, marital status, and the stage of students. The sample included 166 male and female teachers, using Maslach's degree of psychological burnout. The results revealed that the level of psychological burnout for Islamic education teachers was moderate in both emotional exhaustion and depersonalization. However, it was high regarding low personal accomplishment. The results have shown that there is a noticeable difference that male teachers have a higher degree of emotional exhaustion. It has also shown that there were not any statistically distinctive differences according to age of teacher and marital status. In addition, the results have demonstrated that teachers with higher degree, years of experience, and high monthly income are suffering more from psychological burnout.

It is noticed out of the review of related studies that there is a distinctive difference of the degrees of psychological burnout for teachers, as it is sometimes medium as in Alsayed's (2010) study, Mustafa (2004), Alkhrabsheh and Ahmad (2005), and Alsalkhi (2013). It was high as it is in the study of Tawalbeh (1999), Alfrehat and Rabadi (2010), and Alshuyoukh (2011). Third, it was low, as it is in Saeed and Qaryouti (2010). In some studies, the degree of psychological burnout varied, depending on the dimension addressed in the studies of Zghoul, Khraisha, and Khaldi (2003) and Patric, Man, \& Raymond (2005). Neverless, some studies have shown inverse relationship between the individual activity and the strength of accomplishment on the one hand, and the psychological burnout on the other, as it is in the study of Welko and Elvira (2008).

In accordance with the previous contradictory results, here appears urgent need for conducting more studies pertaining to the psychological burnout in the light of some variables, especially for Islamic education teacher in governmental schools. To clarify, the precious study reviewed by the researcher has been applied to teachers of different majors and to Islamic education teachers in private schools in the capital city, Amman. Therefore, this study aims at accounting for the psychological burnout for Islamic education teachers in governmental schools in Maan. The study hopes to add more scientific results to the body of research pertaining to the profession of teaching, in general, and to the teaching of Islamic education, in a narrower sense. 


\section{Method and Procedures}

\subsection{Community of the Study}

The community of the current study is all Islamic Education teachers (120 teachers), males and females, in Ma'an Governorate. A sample has been selected randomly ( 80 teachers) of both genders and equally distributed forming $(66.6 \%)$ of the study's community. Table 2 shows the distribution of subjects according the variables

Table 2. Distribution of the study's sample according to academic level and experience

\begin{tabular}{llll}
\hline The variable & Levels of variation & Number & Percentage \\
\hline \multirow{4}{*}{ Academic level } & Diploma & 5 & 6.4 \\
& BA & 31 & 38.6 \\
& High Diploma & 38 & 47.5 \\
& Masters degree & 6 & 7.5 \\
\hline \multirow{2}{*}{ Experience } & Below 5years & 60 & 68.1 \\
& 5 years and above & 20 & 22.7 \\
\hline
\end{tabular}

\subsection{Tool of the Study}

Arabicized Maslach and Jackson's image has been used to determine the levels of psychological burnout for the subjects of the study as (Tawalbeh, 1999) posited, in which the paragraphs of the third dimension (Low Personal Accomplishment) have been converted to become negative. Agreeing with the first and the second dimensions, Emotional Exhaustion and Depersonalization respectively. Maslach and Jackson's list 1981 is one of the most used measurements of psychological burnout worldwide. It has become very common in studies in foreign languages, moreover, it is used in most studies which tackled the psychological burnout in the Arabic community because of its good psychometric characteristics.

The paragraphs of scale have been built according to the Arabicized versions that the list with its original version consists 22 paragraphs distributed on three sub dimensions:

First: Emotional Exhaustion-this measures the level of exhaustion and stress the subject may feel because of effort exerted to help a specific group in a particular field and has 9 paragraphs.

Second: Depersonalization-this measures carelessness, concernedness, and the negative sense resulting from working with a particular group, and it has 5 paragraphs, forming 10-14 paragraphs.

Third: Low Personal Accomplishment-this measures the method of the individual's self-evaluation and the feeling of ability and satisfaction of his/ her performance. It has 8 paragraphs, forming 15-22 paragraphs.

The paragraphs have been shown on the form of phrases demonstrate the feeling of the teacher toward the career of teaching and he/ she must determine the number of the repeated feeling on the septet scale, as follows:

0-never, 1-sometimes per year, 2-at least once a month, 3-sometimes a month, 4-at least once a month, 5-sometimes in a week, 6-almost every day.

To assure the credibility of the scale, it has been examined by (10) referees who are specialized in Educational Psychology, and Measuring and Evaluation, and in light of their observation and suggestions, required amendments have been done, where some paragraphs are modified. Appendix 1 shows the final version of the scale.

To assure the stability of the scale, stability factor has been calculated by the method of internal consistencyCronbach Alfa. It has been implemented on a sample in the community out of the sample of the study's community (40 subjects) with the correlation coefficient factors were (0.82) for Emotional Exhaustion dimension, (0.80) for Depersonalization dimension, and (0.79) for the dimension of Low Personal Accomplishment. The total value of the coefficient correlation was $(0.85)$ and it was a satisfactory one. 
Table 3. Illustrates the paragraphs distributed on the three dimensions of the Arabicized list of Maslach and Jackson

\begin{tabular}{lll}
\hline The dimension & Paragraphs & The total \\
\hline Emotional Exhaustion & $1,2,3,4,5,6,7,8,9$ & 9 \\
Depersonalization & $10,11,12,13,14$ & 5 \\
Low Personal Achievement & $15,16,17,18,19,20,21,22$ & 8 \\
\hline
\end{tabular}

\subsection{Correction of the List}

Since the alternatives of the paragraph answers vary (0-6), the total score of the general psychological burnout on the list will vary (0-54), the Depersonalization dimension will also vary $(0-30)$ where the respondent score will vary on the dimension of Low Personal Accomplishment (0-48)

To correct the responses of the samples on the paragraphs, Maslach classification used in Tawalbeh's (1999) study has been approved as in the table below:

Table 4. The classification of psycho-burning levels

\begin{tabular}{llll}
\hline \multicolumn{4}{c}{ Levels of psychological burning } \\
\hline Degree & Low & Mid & High \\
\hline Emotional exhaustion & $0-17$ & $18-29$ & $30-54$ \\
Emotional sluggish & $0-5$ & $6-11$ & $12-30$ \\
Low achievement feeling & $0-8$ & $9-14$ & $15-48$ \\
\hline
\end{tabular}

\subsection{Procedures of the Study}

1) Maslach's scale has been improved to implement it on the sample of the study.

2) The sample of the study has been Teachers of Islamic Studies in the Governorate of Ma'an, academic year 2013-2014

3) The scale has been tried on a pilot study from the community of the study out of the subjects of the original study group to assure the psychometric characteristics of the scale.

4) The scale has been implemented on the sample of the study.

5) The scale has been used in the spring semester 2013-2014.

6) The responses of the samples have been recorded on the scale and have been analyzed using the statistical package program (SPSS) to answer the questions.

\subsection{The Variables of the Study}

This study is considered as a descriptive survey includes one basic variable which is the level of psychological burnout for Islamic Education teachers in Ma'an. The variable is measured by the score of the teacher on the scale prepared for the purpose of this study which includes three dimensions: Emotional Exhaustion, Depersonalization, Low Personal Accomplishment. It also includes the following variables:

1) Academic Level: (Diploma, BA, Higher Diploma, MA).

2) Years of Experience: two levels-(less than 5 years and more than 5 years).

\subsection{Statistical Treatment}

To answer the questions of the study, the mean and standard deviation s of the teachers' estimations have been extracted on the three dimensions, test $(\mathrm{T})$ has also been used to determine the presence of the differences between the means of the teachers' estimations for the psychological burnout levels and have been attributed to the academic level. ANOVA has also been used to determine the presence of variances in the teachers' estimations for psychological burnout level and have been attributed to the years of experience. 


\section{Results of the Study and Discussion}

Results of the first Question: What is the level of psychological burnout of teachers of Islamic Education in Ma'an on Maslach's Scale with its three dimensions.

Table 5 shows the means and standard deviations of the responses of the teachers' of Islamic Education to the paragraphs classified according to the level of psychological burnout within each dimension in the list to the teachers.

Table 5. Means, standard deviations, and levels of psychological burnout of the sample of the study

\begin{tabular}{cccccc}
\hline Dimension & Statistical & \multicolumn{4}{c}{ Class } \\
\hline Emotional Exhaustion & & Low & Moderate & High & Total \\
& Number & 40 & 35 & 5 & 80 \\
& Mean & 14.70 & 22.09 & 33.71 & 22.48 \\
& Standard Deviation & 2.71 & 3.02 & 1.72 & 8.92 \\
Depersonalization & Number & 49 & 26 & 4 & 80 \\
& Mean & 8.05 & 11.30 & 21.5 & 9.96 \\
& Standard Deviation & 2.16 & 2.00 & 0.50 & 4.59 \\
Low Personal Accomplishment & Number & - & - & 80 & 80 \\
& Mean & - & - & 24.27 & 24.27 \\
& Standard Deviation & - & - & 9.64 & 9.64 \\
General Psychological Burnout & Number & 68 & 11 & 1 & 80 \\
& Mean & 46.14 & 75.0 & - & 46.71 \\
& Standard Deviation & 5.73 & - & - & 7.25 \\
\hline
\end{tabular}

It is observed in Table 5 that the mean of the responses of the teachers of Islamic Education to the paragraphs of the Emotional Exhaustion has reached (22.48) which indicate that they suffer moderate level of Emotional Exhaustion. The mean of depersonalization dimension responses have reached (8.92) which gives hint that the teachers of Islamic Education suffer low level in this dimension.

The Low Personal Accomplishment responses' mean has reached (24.27) which indicate that teachers suffer lack of the Low Personal Accomplishment. But, for the general psychological burnout mean of responses has been (46.71) which shows tendency to moderation.

Table 5 shows that the level of psychological burnout of teachers of Islamic Education in Ma'an was moderate on both Emotional Exhaustion and Low Personal Accomplishment dimensions. On the other hand, the mean of Depersonalization was low according to the classification in Table 4.

The result can be attributed to the fact that teachers of Islamic Education teach on the basis of loyalty to Allah in their jobs. In addition, they believe that the process of teaching is the most noble and beloved career to Allah. The teachers of Islamic Education also believe that being patient in their job and taking hardship and facing difficulties for the sake of teaching students and protecting them from deviation factors will be rewarded on it. The teacher in the secondary stages does not suffer explaining the Islamic concepts to students because students' thinking abilities are different from those in the primary stages, and his thinking abilities are tangible which is effort demanding for the teacher and may lead to psychological burnout of teachers. This result agrees with the Al Salkhy (2013), Al Sayed (2010), and Patrick, Man, and Raymond (2005) who demonstrates the presence of moderate level in the Emotional Exhaustion and the Psychological burnout in general. The study differs that of Shyokh (2011), Tawalbeh (1999), Zghoul, Khraisha, and Khaldi (2003), Mustafa (2004), Alfrehat and Rabadi (2010), and Kharabsheh and Ahmad (2005).

The results of the second question answer: Are there statistical differences on $(\alpha=0.05)$ in the level of psychological burnout of teachers attributed to the variable of academic level and years of experience?

To answer this question, the means and standard deviation s to the responses of teachers in all classes of the qualifications have been calculated as shown in Table 6 . 
Table 6. Means and standard deviations to the teachers' responses to the paragraphs of the psychological burnout list dimensions classified according the qualification variable

\begin{tabular}{lllllll}
\hline Dimension & Statistical & Diploma N=5 & BA (N 31) & Higher Diploma (N 38) & MA (N 6) & Total (N 80) \\
\hline \multirow{2}{*}{ Emotional Exhaustion } & Mean & 20.0 & 31.42 & 21.31 & 20.0 & 21.17 \\
& Standard Deviation & 9.05 & 5.99 & 9.78 & 6.71 & 8.10 \\
\multirow{2}{*}{ Depersonalization } & Mean & 6.75 & 6.90 & 8.26 & 6.71 & 7.53 \\
& Standard Deviation & 0.96 & 4.15 & 2.61 & 1.98 & 3.24 \\
\multirow{2}{*}{ Low Personal Accomplishment } & Mean & 17.25 & 19.87 & 20.41 & 15.71 & 19.64 \\
& Standard Deviation & 9.64 & 4.21 & 10.25 & 4.42 & 7.96 \\
\multirow{2}{*}{ General Psychological Burnout } & Mean & 44.0 & 48.19 & 49.97 & 42.43 & 48.34 \\
& Standard Deviation & 6.05 & 9.22 & 12.87 & 4.20 & 10.89 \\
\hline
\end{tabular}

It is clear from Table 6 the presence of the clear differences between the means of responses of the teachers to the paragraphs of the dimensions of the psychological burnout list based on the differences in qualification degree. It is also observed in this table that the mean of the teachers' responses on the Emotional Exhaustion dimension represent the moderation in general regardless the degree, where the responses of teachers to the paragraphs of Depersonalization tend to be low regardless the qualification degree. The results of Low Personal Accomplishment paragraphs indicate that the mean of responses tend to be generally high which means that the teachers suffer Low Personal Accomplishment regardless the qualification degree. For the General Psychological Burnout, it is clear that the results of responses tend to be low regardless their degree that can be attributed to the concepts of Islamic Education which are abstract and difficult. The teacher needs to discuss the concept again and again so it leads to shortage of eagerness then to the feeling of low personal accomplishment.

To uncover the differences between the responses of the teachers to the paragraphs of the psychological burnout list according to the variable of qualification (Diploma, BA, Higher Diploma, MA), one way variance has been used $(1 \times 4)$. Table 7 illustrates the results of the analysis of the one way variance $(4 \times 1)$ to the differences between the responses means of teachers to the paragraphs of psychological burnout preceding the differences in the levels of degree.

Table 7. The results of the analysis of the one way variance $(4 \mathrm{x} 1)$ to the differences between the responses means of teachers to the paragraphs of psychological burnout preceding the differences in the levels of degree

\begin{tabular}{llllll}
\hline Dimension & Source of Variance & M.M. & D.H. & M.M.M & "F" Value \\
\hline Emotional Exhaustion & Among Groups & 17.724 & 3 & 5.908 & 0.087 \\
& Inside Groups & 5227.856 & 77 & 67.894 & \\
& Total & 5245.580 & 80 & & \\
Depersonalization & Among Groups & 39.849 & 3 & 13.283 & 1.275 \\
& Inside Groups & 802.324 & 77 & 10.420 & \\
& Total & 842.324 & 80 & & \\
Low Personal Accomplishment & Among Groups & 155.519 & 3 & 51.84 & \multirow{2}{*}{0.812} \\
& Inside Groups & 4917.098 & 77 & 63.858 & \\
& Total & 5072.617 & 80 & & \\
General Psychological Burnout & Among Groups & 424.794 & 3 & 141.598 & 1.203 \\
& Inside Groups & 9065.527 & 77 & 117.734 & \\
& Total & 9490.321 & 80 & & \\
\hline
\end{tabular}

It is evident from Table 7 the non-existence of statistical differences between the means of teachers' responses to the paragraphs of psychological burnout list, according to the difference in qualification degrees on any 
dimension or the total degree which represents the general psychological burnout which means that the variable of qualification is not considered as a variable which cannot lead to differences in the level of burnout with teachers.

\section{Recommendations}

1) Designing and implementing protective and remedial programs to help teachers teach the concepts of Islamic Education and empower them with strategies that should be followed in teaching.

2) Holding courses before and in employment about the requirements and the circumstances of teaching concepts of Islamic Education.

3) Conducting more studies to find the reasons behind the feeling of teachers of psychological burnout in the field.

\section{References}

Albatal, Z. (2000). Psychological Burnout (psychological pressures of work) to the teachers of special education, what it is-causes-cured. Series versions of Special Education Academy, Riyadh, Saudi Arabia.

Alfrehat, A., \& Rabadi, W. (2010). Psychological burnout levels of kindergarten teachers in Ajloun. Najah University for Humanities Research Journal, 24(5).

Badawi, A. B. A. (2006). Professional standards and their role in the organization and workforce development. Paper presented to the meeting of experts on the Arab-indeed professional standards and hoped the Arab Labor Organization/Cairo.

Bakker, A., Schanfeli, W., Sixma, H., Bosveld, W., \& Van, D. (2000). patient demands, lack of reciprocity and burnout: A five year longitudinal study among general practitioners. Journal of Organization Behavior, 21, 425-441. http://dx.doi.org/10.1002/(SICI)1099-1379(200006)21:4<425::AID-JOB21>3.0.CO;2-\#

Bilge, F. (2006). Examining the Burnout of Academics in Relation to Job Satisfaction and Other Factors. Social Behavior and Personality. Retrieved from http://www.Sbp-journal.com

Cano-Garcia, F. J., Padilla-Munoz, E. M., \& Ortiz, M. A. (2005). Personality and Contextual Variables in teacher burnout. Personality and Individual Differences, 38, 929-940. http://dx.doi.org/10.1016/j.paid.2004.06.018

Gugliemi, R. S., \& Tatrow, K. (1998). Occupational stress burnout and health in teachers-A methodological and theoretical analysis. Review of Educational Research, 68(1), 61-99. http://dx.doi.org/10.3102/00346543068001061

Hargreaves, A., \& Shaw, P. (2001). Knowledge and skills development in the economies of developing countries and countries in transition to a market system. An analytical study for the international Bank/UK Department for International Development on the knowledge and skills required in the modern economy Educational Training.

Hayek, H. (2000). Combustion levels of computer teachers in the Jordanian public schools (Unpublished MA thesis). Yarmouk University, Irbid, Jordan.

Jaroudi, M. (2008). A seminar on apprenticeship education and the Ministry of Education, Saudi Arabia.

Kharabsheh, O., \& Ahmed, A. (2005). Psychological Burnout among teachers working with students with learning difficulties in resource rooms. Umm Al-Qura University Journal of educational and social sciences and humanities, 17(2), 293-331.

Kloke, J., \& Smith, K. (2005). Resolve conflicts at work: A Complete Guide for each person at work. Translation Jarir Bookstore, Riyadh Saudi Arabia.

Maher, E. (1983). Burnout and Commitment-A theoretical Alternative. Personnel \& Guidance Journal, 61(7), 390-393.

Mustafa, M. M. (2004). The degree of psychological burnout among teachers of secondary school in Khartoum state in the light of some of the demographic and professional variables.

Nasser, I. (2000). Foundations of education. Dar Al-Ammar for publication and distribution, Amman, Jordan.

Noushad, P. (2008). From Teacher Burnout to Student Burnout. Farook Training College, Calicut, Kerala, India.

Patrick, L., Man, Y., \& Raymond, C. (2005). Do Demographic Characteristics Make a Difference to Burnout among Hong Kong Secondary School Teachers. Social Indicators Research, 71(1-3), 491.

Rashdan, M. (1995). Psychological Burnout among faculty members in the Jordanian public university and its 
relationship with some variables (Unpublished MA thesis). Yarmouk University, Irbid, Jordan.

Saeed, A,. \& Qaryouti, I. (2010). Psychological Burnout among teachers of students with learning difficulties in the Sultanate of Oman. Jordan Journal of Educational Sciences, 6(3), 175-190.

Schonfeld, I. S. (2001). Stress in 1st-year Woman teachers. The context of social support and coping. Genetic, Social, and General Psychology Monographs. Journal of Occupational Behavior, 127, 133-168.

Schulz, C. (2007). Alternative certification and the second career professional-How to get more of a good thing.

Tawalbeh, M. (1999). Levels of Psychological Burnout among computer teachers in the provinces of Irbid, Mafraq, Jerash and Ajloun school. Muta Research Studies, 14(2), 169-195.

Tina, M. (2008). Teacher Stress and Burnout and the Role of physical Activity and parent Involvement. A Thesis, Submitted in partial Fulfillment of the Requirements for the Degree of Masters of Arts in psychology Department of psychology. Central Connecticut State University, New Britain, Connecticut.

Welko, T., \& Elvira, T. (2008). Existential fulfillment and burnout among principals and teachers. Journal of Beliefs and Values, 29(1), 11-27.

Zghoul, R., Khresha, M., \& Khalidi, M. (2003). Psychological Burnout among teachers and its relationship to the perception of the leadership style of principals Karak secondary schools. Muta for Research and Studies, $18(6), 243-268$.

\section{Appendix}

\section{Tool of the Study}

\begin{tabular}{|c|c|c|c|c|c|c|c|c|}
\hline \multirow[b]{2}{*}{$\begin{array}{l}\text { Item } \\
\text { No. }\end{array}$} & \multirow[b]{2}{*}{ Item } & \multicolumn{7}{|c|}{ Degree of Applicability } \\
\hline & & Never & $\begin{array}{l}\text { Several } \\
\text { Times } \\
\text { Yearly }\end{array}$ & $\begin{array}{l}\text { At east } \\
\text { once } \\
\text { Monthly }\end{array}$ & $\begin{array}{l}\text { Several } \\
\text { Times } \\
\text { Monthly }\end{array}$ & $\begin{array}{l}\text { At east } \\
\text { once } \\
\text { Weekly }\end{array}$ & $\begin{array}{l}\text { Several } \\
\text { Times } \\
\text { Weekly }\end{array}$ & $\begin{array}{l}\text { Approximately } \\
\text { Everyday }\end{array}$ \\
\hline 1 & $\begin{array}{l}\text { I feel that I cannot } \\
\text { suppress my } \\
\text { emotions while } \\
\text { practicing } \\
\text { teaching } \\
\text { profession }\end{array}$ & & & & & & & \\
\hline 2 & $\begin{array}{l}\text { I feel fully } \\
\text { exhausted at the } \\
\text { end of a business } \\
\text { day. }\end{array}$ & & & & & & & \\
\hline 3 & $\begin{array}{l}\text { I feel tired at the } \\
\text { beginning of each } \\
\text { business day. }\end{array}$ & & & & & & & \\
\hline 4 & $\begin{array}{l}\text { I feel nervous } \\
\text { when dealing with } \\
\text { students day long. }\end{array}$ & & & & & & & \\
\hline 5 & $\begin{array}{l}\text { I feel annoyed and } \\
\text { bored due to my } \\
\text { work. }\end{array}$ & & & & & & & \\
\hline 6 & $\begin{array}{l}\text { I feel frustrated } \\
\text { due to the nature } \\
\text { of my career. }\end{array}$ & & & & & & & \\
\hline 7 & $\begin{array}{l}\text { I practice my work } \\
\text { with hardship and } \\
\text { exhaustion. }\end{array}$ & & & & & & & \\
\hline
\end{tabular}




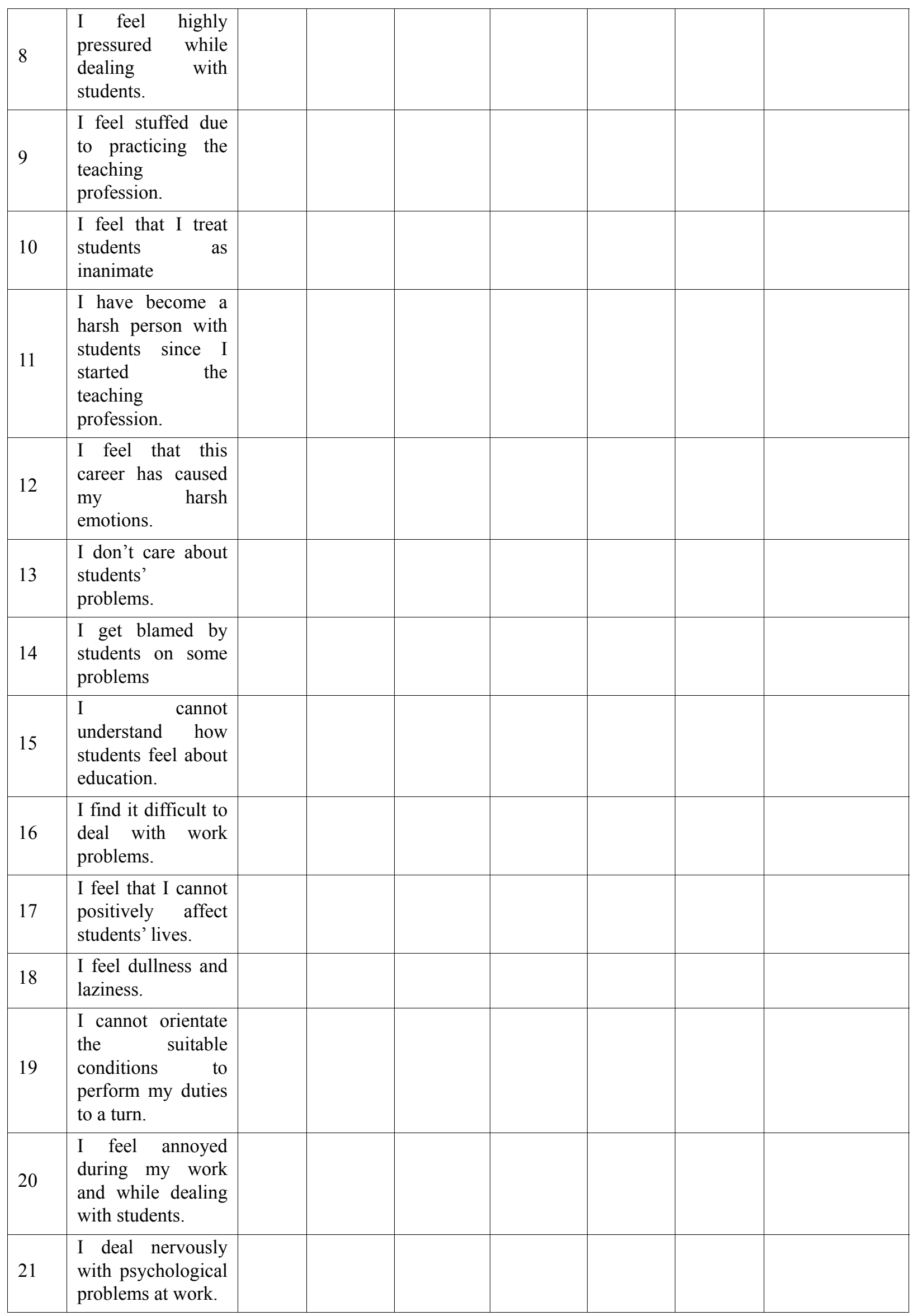




\begin{tabular}{|l|l|l|l|l|l|l|}
\hline 22 & $\begin{array}{l}\text { I couldn't make } \\
\text { distinguished } \\
\text { things at the } \\
\text { teaching } \\
\text { profession. }\end{array}$ & & & & & \\
\hline
\end{tabular}

\section{Copyrights}

Copyright for this article is retained by the author(s), with first publication rights granted to the journal.

This is an open-access article distributed under the terms and conditions of the Creative Commons Attribution license (http://creativecommons.org/licenses/by/3.0/). 